\title{
Literatura negra sob a perspectiva semiótica: o dito e o não-dito
}

\author{
Silvia Regina LORENSO Castro (Mestranda-USP/Fundação Ford)
}

RESUMO: Para a semiótica, o texto é um todo de significação capaz de reunir, ainda que parcialmente, as condições contextuais de sua leitura. Seguindo essa orientação, esse capítulo procura depreender o processo de valorização temática e figurativa na construção de narrativas literárias produzidas por enunciadores criadores de uma poética chamada afro-brasileira. Integram essa poética algumas propostas literárias que se desenvolvem em diferentes percursos. Um desses percursos está indicado nas 27 edições dos Cadernos Negros, publicados pela organização Quilombhoje, em São Paulo. Com vistas ao trabalho de análise recorremos às concepções teóricas da semiótica greimasiana. Como aporte complementar, fazemos uso da proposta dos regimes de interação e estilos de vida, de Eric Landowski, com objetivo de esboçar uma tipologia da enunciação negra na literatura brasileira.

PALAVRAS-CHAVE: semiótica; enunciação negra, literatura; poesia, identidade.

ABSTRACT: Acoording to semiotics paradigms, the text is a whole of signification that is capable of congregating, even if only partially, the context conditions that enables its comprehension. Within that perspective, this article aims at identifying the process of thematic and figurative valorization in the construction of literary narratives produced by enunciators who create an Afr-Brazilian poetics. That poetics is formed by different literary propositions that are developed in distinct styles. One of those styles is articulated in 27 editions of Cadernos Negros (Black Notebooks) published by the organization Quilombhoje in Sao Paulo. The proposed analysis is guided by Greimas' theorical conceptions and it is complemented by Eric Landowski's model of regimes of interaction. This study seeks to delineate a typology of Black enunciation in Brazilian literature.

KEYWORDS: Semiotics; black enunciation; literature, poetry, identity. 


\title{
Uma escrita silenciada
}

No texto "A escrita e os excluídos", Bosi (2002) sugere dois caminhos para considerar o ato de escrever como um ato de cidadania para aqueles que estão alijados do processo de produção simbólica: o primeiro consiste em ver o excluído social ou marginalizado como objeto da escrita. Ser objeto compreende ser tema, personagem, situação narrativa. Outra maneira é entender esse mesmo sujeito como enunciador do processo simbólico. Essa última proposição parte da "hipótese de que é possível identificar, na dinâmica dos valores vividos em contextos de pobreza, certas motivações que levem à atividade social da leitura e da escrita. Trata-se de descobrir o leitor escritor potencial (Bosi, 2002:261)." Tenciona o enunciador pensar o excluído como agente virtual da escrita. Tais postulados se inserem no campo de preocupação de Pereira (2002) ao cunhar a expressão literatura silenciosa para falar desse perfil de literatura que o cânone literário não alimenta expectativa de diálogo. Segundo ele

\begin{abstract}
A literatura silenciosa constitui lugar a partir do qual os indivíduos destituídos de voz, por força das desigualdades sociais (e raciais), estabelecem a sua auto-representação. Ao tecerem as estratégias dessa literatura, realizam-se como sujeitos da comunicação, isto é, manejadores de códigos através dos quais respiram e colocam em prática seus projetos de superação da exclusão social. (p.38)

(...)

a expressão literatura silenciosa adquire um significado paradoxal, pois indica uma textualidade que está ausente dos espaços literários legitimados, mas que ao mesmo tempo, insinua-se como uma presença em potencial. Trata-se de uma situação que resulta da construção de uma ausência e de uma presença incompletas, ou seja, os discursos que debatem essa textualidade fixam-se numa faixa, sem negar de todo a outra. (p.42)
\end{abstract}

Há uma constante polêmica sobre a qualidade dos textos produzidos por enunciadores negros. Por um lado, etnógrafos, sociólogos e antropólogos atribuem-lhe a valorização prática - como nos diria Jean Marie Floch - e elogiam seus sinais de função estética. Por outro lado, a crítica literária a ignora solenemente. Ainda segundo Pereira (2002, p.43), a ênfase nos aspectos literários dessa literatura posta em silenciamento não implica ignorar sua instância documental, nem vice-versa

Pode-se dizer que a literatura silenciosa mantém seu significado políticoporque, em suas origens, refere-se à textualidade de grupos marginalizados, mas exige a compreensão do significado estético que faz da alusão ao silêncio o pretexto para garantir a tessitura de um discurso complexo e criativo.

Em suma, é necessário ler as narrativas poéticas da literatura negra conferindo a devida atenção à oposição entre seu plano de conteúdo (o valor histórico-social devidamente figurativizado e tematizado) e seu plano de expressão (como realização estética), que utiliza estrategicamente determinados recursos para produzir os efeitos de sentido desejado. De qualquer modo, a literatura negra reclama uma abordagem que é 
muito cara à semiótica: a noção segundo a qual o sentido é gerado pela diferença, pela relação entre, pelo menos, dois termos com um mínimo de relação.

Grosso modo, a literatura dita canônica, porque legitimada, e a literatura posta em silenciamento são, ambas, elaborações sociais relacionadas à atribuição, à construção e, porque não, a desconstrução de sentido ao mundo. Cada uma adota os recursos que lhes são mais convenientes com vistas a alcançar os efeitos de sentido que desejam. Porém, longe de ser essa uma experiência comprovada, mesmo a mais desatenta visita aos cursos de Letras, aos manuais de literatura, aos livros didáticos, às indicações para leitura de livros para o vestibular, e na maioria dos ensaios de teoria literária percebe-se a completa ausência da literatura negra produzida no Brasil. Essa ausência homologa-se à situação do povo negro, conforme nos diz Fonseca (2000:90)

\begin{abstract}
o negro foi ignorado por movimentos de feição nativista que fizeram do índio o símbolo da identidade do país, ainda que figurado como emblema de uma natureza exuberante e soberana, quase sempre vista à distância, como pano de fundo do ideal de nacionalidade. Por isso, mesmo em projetos de feição ufanista que exaltavam acriticamente os valores e tradições nacionais, identifica-se uma ideologia de exclusão do diferente, que aprisiona o negro em lugares e funções marginais.
\end{abstract}

\title{
Estudo das tipologias da enunciação negra
}

Com o objetivo de romper com a invisibilidade do negro e questionar o propalado mito da democracia racial, o movimento social negro brasileiro investiu, no final da década de 70, em uma série de manifestações corporificadas em denúncias e protestos públicos. Tencionava esse movimento entrar em disjunção com a data oficial de comemoração da abolição da escravidão (13 de maio), e afirmar a conjunção com a data na qual, diz a história, o líder negro palmarino - Zumbi dos Palmares - foi assassinado (20 de novembro). Ao propor essa mudança no campo da simbologia nacional, suas lideranças anunciavam uma nova postura diante da realidade social brasileira: a construção de novos discursos e de novas práticas protagonizados, agora, pelos próprios negros e, não mais por narrativas encenadas por brancos. Em meio a esses fatos, nascia em 25 de novembro de 1978, Cadernos Negros, uma antologia com oito autores, trazendo a marca do esforço de superar a "geração do mimeógrafo", como diz Alves (2002:222). No prefácio assinado coletivamente, presenciamos a seguinte definição:

Cadernos Negros marca passos decisivos para nossa valorização e resulta de nossa vigilância contra as idéias que nos confundem, nos enfraquecem e nos sufocam. As diferenças de estilo, concepções de literatura, forma, nada disso pode mais ser muro erguido entre aqueles que encontram na poesia um meio de expressão negra. Aqui se trata da legítima defesa dos valores do povo negro. A poesia como verdade, testemunha do nosso tempo.

Uma característica fundante da literatura negra presente em Cadernos Negros é a opção por organizar a voz coletivamente. Tal atitude contrasta com a opção 
colonizadora cuja tática foi dividir as etnias africanas trazidas para o Brasil, para melhor dominá-las. Em meados da década de 80, Cadernos Negros passam a ser chamados de Quilombhoje Literatura e novos membros são agregados. As publicações são anuais, contam com recursos próprios e alternam, nas vinte e sete edições, poesia e prosa. Em seu livro A poesia afro-brasileira, Bastide (1943) revisita nossa "tradição letrada" partindo de uma perspectiva étnica, para destacar as obras de negros e mestiços. Na introdução do volume, chama a atenção para a especificidade desta poesia, invocando como pressuposto não apenas a diferença cultural, mas também as contingências históricas inerentes à presença dos africanos e seus descendentes no Brasil. Segundo Duarte (2001:38), Bastide acredita que "algo resiste nos afro-descendentes que sobrevive à assimilação e os faz escaparem do etnocídio. Tal processo de superação histórica leva-os a aprender a língua do colonizador sem esquecer formas, narrativas e crenças do passado livre."

Já a pesquisa de Rabassa (1965), na seqüência do estudo de Sayers (1958), deixa em segundo plano a questão da autoria. Ambos os trabalhos, concebidos originalmente como teses de doutoramento para universidades norte-americanas, investem atenção menos no negro como sujeito da enunciação e mais como figura representada nos textos literários. Sayers enfoca a narrativa pré-abolicionista, enquanto Rabassa enfatiza a produção posterior a 1888, indo até meados do século XX. Em 1973, Roger Bastide publica Estudos Afro-brasileiros, no qual ele demonstra um panorama sociológico da situação do negro no Brasil, visto a partir de três elementos: a imprensa negra em São Paulo, a poesia afro-brasileira conjugada com a análise dos estereótipos de negros na literatura brasileira e as religiões de matriz africana.

Continuando a trajetória do negro na literatura brasileira, pesquisadores apontam percursos baseados em simulacros metodológicos diferenciados. Brookshaw (1983:152) nos informa que C. L. Innes definiu três modos de presença no mundo:

$1^{\mathrm{a}}$. o escritor poderia ocultar tão habilmente sua identidade e orgulhar-se de sua aptidão para escrever, que nenhum crítico poderia adivinhar sua origem;

$2^{\text {a }}$. ele poderia escrever como um nativo, utilizando as formas dialetais herdadas e os dois pontos principais, humor e ternura; ou

$3^{\mathrm{a}}$. poderia protestar abertamente contra a linguagem e a forma literária há muito sancionadas pela tradição européia.

Utilizando essa tipologia, Brookshaw ilustra cada uma das atitudes com exemplos de escritores afro-brasileiros. Foram enquadrados na primeira caracterização, Machado de Assis (segundo o autor, ele é criador de uma obra literária totalmente divorciada de suas origens raciais); Cruz e Sousa (cujas referências à raça, conforme aponta Brookshaw, são camufladas por uma espessa floresta de símbolos) e Tobias Barreto (cujo escape intelectual das origens raciais era manifestado por seu grande interesse pela filosofia e cultura alemã). Domingos Caldas Barbosa trataria de escrever como um nativo, encampando a segunda atitude. Finalmente, o protesto aberto estaria presente nas obras de Lima Barreto e Luiz Gama.

Em 1987, o escritor Oswald de Camargo publica o livro O Negro Escrito: apontamentos sobre a presença do negro na Literatura Brasileira. Nessa obra, 
encontramos exemplos de "estilos de vida" que povoaram e ainda povoam o cenário da literatura, seja ela canônica ou não-canônica, muito próximos da tipologia apresentada por Brookshaw.

Em diálogo com a proposta de Martins (1995a) a respeito do teatro negro, a tipologia de Proença Filho (2004:161) apresenta a trajetória do negro na literatura brasileira demarcada em dois momentos: "a condição negra como objeto, numa visão distanciada, e o negro como sujeito, numa atitude compromissada." Como objeto da enunciação, o negro aparece, via de regra, em papéis actanciais estereotipados (Proença Filho, 2004:174)

\begin{abstract}
ora como elemento perturbador do equilíbrio familiar ou social, ora como negro heróico; ora como negro humanizado, amante, força de trabalho produtivo, vítima sofrida de sua ascendência, elemento tranqüilizante integrador da gente brasileira (em processo de embranquecimento), em termos de manifestações. Zumbi e a saga quilombola não habitam destaques nesse espaço.
\end{abstract}

Zilá Bernd (1888) enfatiza Luiz Gama como aquele que instaura pistas de um discurso fundador e pioneiro da atitude compromissada com os valores da negritude. Ela destaca o livro Primeiras Trovas Burlescas, de Gama, publicado em 1859, como um momento de rompimento de um continum na Literatura Brasileira, na medida em que funda uma linha de indagação a respeito da identidade, a qual será trilhada até hoje pela poesia negra do Brasil. Como enunciador discursivo o ator da enunciação adota procedimentos figurativos e temáticos que propõem um novo olhar sobre a saga negra na América, especialmente em solo brasileiro. Da variedade temática, fiquemos apenas com um dos mais recorrentes: a afirmação da identidade de matriz africana, através de figuras como exaltação do cabelo crespo, de instrumentos musicais - a exemplo do tambor, de performances corporais, ritualísticas e religiosas - capoeira, congado, candomblé, entre outras. Mais tarde retornaremos ao assunto. Por ora, esboçamos uma proposta de aplicação do simulacro metodológico, criado por Eric Landowski (2002), a fim de dialogar com as propostas apresentadas anteriormente. $\mathrm{O}$ autor recorre a uma "metáfora zoossocial" para explicar o que vem a ser os "estilos de vida e os regimes de interação." Vejamos como tal simulacro funciona na discussão sobre a enunciação negra na literatura.

\title{
Regimes de Interação \& Identidade vs. Alteridade
}

O conceito de regimes de interação retoma a idéia de sentido e diferença na perspectiva de Saussure. Assim, homem existe em oposição à mulher, dia existe em oposição à noite, preto existe em oposição a branco. O mesmo ocorre com a idéia de sujeito na qual o um opõe-se a um outro. Segundo Landowski (2002:04)

o que dá forma à minha própria identidade não é só a maneira pela qual, reflexivamente, eu me defino (ou tento me definir) em relação à imagem que outrem me envia de mim mesmo; é também a maneira pela qual, transitivamente, objetivo a alteridade do outro atribuindo um conteúdo 
específico à diferença que me separa dele. Assim, quer a encaremos no plano da vivência individual ou - como será o caso aqui - da consciência coletiva, a emergência do sentimento de "identidade" parece passar necessariamente pela intermediação de uma "alteridade" a ser construída.

A reflexão semiótica sobre identidade vs. alteridade se ajusta às novas dimensões de direitos e cidadania que caracterizam as sociedades democráticas na virada do milênio, cuja afirmação da diferença, da alteridade, da rica geografia de identidades culturais não pode mais ser vista apenas como uma categoria semântica fundamental. Agora, a busca da identidade pressupõe o seguinte encaminhamento de Landowski (2002:27): "eu sou o que você não é, sem dúvida, mas eu não sou somente isso; sou também algo a mais, que me é próprio - ou que talvez nos seja comum." Essa concepção de relação intersubjetiva pressupõe tanto o $\mathrm{eu}$ quanto o outro em movimento, alternância de continuidade e ruptura o tempo todo; não há duratividade. A tensão é resultado da relação e, por conseguinte, gera a diferença, ao mesmo passo em que é gerada por ela.

O semioticista recorre à metáfora zoossocial para explicar estilos de vida dos sujeitos na sua relação com o outro. Para ele, há quatro tipos de sujeitos em interação: ao sujeito em conjunção com as normas do grupo a que pertence, o autor chamou de esnobe, isto é, um indivíduo que se caracteriza essencialmente por seu senso de adequação: demonstrando o comportamento de identificação quanto às normas do grupo ao qual pertence. O segundo perfil é denominado dândi, típico ser "disposto a tudo, ao contrário, para se diferenciar e se desligar - se disjuntar - da mesma sociedade". O camaleão é o nome atribuído ao terceiro perfil. A habilidade do camaleão "consiste, muito discretamente, em se fazer passar por alguém que já pertence ao mesmo mundo, embora, na realidade, ele jamais tenha se disjunto" completamente. Ele marca a negação da identificação. Por fim, nosso último perfil de estilo de vida é o urso, "este solitário - louco ou gênio - a quem ninguém senão ele próprio pode indicar a direção a seguir e que, uma vez a caminho, não se desviará, haja o que houver, de sua própria trajetória"; este não quer entrar em conjunção com nada que esteja ligado ao mundo social; seu percurso é solitário. A singularização é sua marca principal. $\mathrm{O}$ autor nos lembra, no entanto, que esses espaços não são totalmente rígidos e absolutamente inflexíveis. Assim, "na encruzilhada dos percursos que acabamos de esboçar, todos os pontos de chegada são ao mesmo tempo outros pontos de partida possíveis para algum outro" (2002:40).

Cruzando essas informações com a noção de modalidades narrativas, Landowski dirá que os efeitos de sentido projetados pelo simulacro do urso e pelo simulacro do camaleão são modalizados por um querer-ser que se opõe a um quererparecer atribuído ao simulado do esnobe e ao do dândi. O urso não "se preocupa a mínima com o olhar, indiferente ou curioso, aprovador ou desaprovador, de outrem; o camaleão, administrando habilmente as aparências de modo a nada deixar transparecer de sua alteridade intrínseca relativamente ao meio ambiente". O esnobe procura não apenas ser, mas também ele precisa parecer que é igual ao grupo de origem; o dândi tem "a obsessão, inversa, de se demarcar e, portanto, até um certo ponto, de se excluir de seu próprio meio", fazendo o possível para parecer diferente, distinto do seu grupo de pertença. 
Como dissemos anteriormente, os regimes de interação não são estáticos e inflexíveis; eles podem mudar conforme mudem as configurações nas relações de identidade vs. alteridade. Nesse sentido, propomos dois sistemas de interação na produção literária brasileira, uma legitimada pelo cânone, e a outra, inscrita em uma via alternativa. Temos, pois, dois modelos de projeção dos estilos de vida. O primeiro modelo aponta para os enunciados orientados pelo paradigma estético canônico ocidental, cujo efeito de sentido demarca menos questões éticas que estéticas. $\mathrm{O}$ segundo modelo apresenta o paradigma alternativo, de matriz negra, e propõe o diálogo entre o ético e o estético. Lembremo-nos, porém, que ambas as posições representam posturas ideológicas muito bem demarcadas, embora o primeiro modelo crie o simulacro da objetividade; o que não é senão efeito de discurso, ilusão referencial. O primeiro modelo, em nome da liberdade de expressão e da licença poética, faz crer que é a única matriz estética possível. Assim como acontece no teatro negro, o segundo modelo vem apontar outras matrizes de criação de linguagens, as quais, para além de apenas enfatizarem o tema do negro, trazem, com o sujeito da enunciação, uma história, um pensamento estético, enfim, uma cosmovisão (Martins, 1995).

Vale a pena recorrermos a extratos da nossa literatura, revisitando os percursos de interação conjugados com estilos de vida dos enunciadores, conforme as teorias de Landowski. Se tomamos o modelo canônico como referência, quais escritores projetam, respectivamente, os simulacros esnobe, dândi, camaleão e urso?

\begin{aligned} Estilo & \multicolumn{1}{c}{ Estilo } \\ Esnobe & Dândi \\ Conjunção & Disjunção \\ & \\ & \\ Não-disjunção & Não-conjunção \\ Estilo & Estilo \\ Camaleão & Urso \end{aligned}

No campo da literatura, o "esnobe" seria aquele enunciador que afirma a conjunção total com o paradigma estético canônico e projeta no enunciado seu lugar enunciativo. Retomando Landowski, ele não apenas é ou quer ser o destinador da boa forma; ele quer-parecer que é; seu trabalho literário é recoberto de preocupações com a polidez e com a elegância formal. $\mathrm{O}$ esnobe mantém a postura clássica de obediência tradicional aos valores do cânone. Com efeito, não seria ocioso citar Machado de Assis como um importante exemplo do jeito esnobe de ser, conforme o primeiro marco referencial. Sua obra é a conjunção com o culto à forma, com a matriz ocidental da estética literária. O lugar enunciativo de Machado de Assis sempre desperta polêmicas a respeito de sua vida e obra. Alguns críticos e outros estudiosos da literatura tentam entender como está circundada a temática negra nos seus trabalhos. Tal especulação se deve ao fato de ele ser mulato, e cujos trabalhos foram produzidos sob a vigência da escravidão. Sobre o assunto anota Camargo (1987:54)

o destino empurrava Machadinho às cercanias de negros - fosse no campo de afeto e matalotagem para a vida, fosse no campo do aprendizado e despertar 
para as Letras. Foi Paula Brito (precursor da imprensa negra no Brasil) que, tendo Machadinho menos de 16 anos, publicou o primeiro trabalho literário dele. (...) E é pelas mãos do mesmo Paula Brito que o menino Machado entrou, em 1856, para a 'Tipografia Nacional.

Esse contato de Machado com o universo negro antes e depois da abolição da escravidão, ao que sugere a projeção enunciada na sua obra, não influenciou, de maneira significativa, conforme nos conta Sayers (1983:385), sua veia literária, e não foi suficiente para que ele

\begin{abstract}
emprestasse seu talento à causa do negro, à luta contra a escravidão, como o fizeram outros mulatos bem dotados, tais como José do Patrocínio e Luís Gama. Ou tivesse, pelo menos, desenvolvido o tema de Salomé Queiroga e Bernardo Guimarães, de que o tipo de brasileiro genuíno fosse mestiço de negros, escrevendo romances com protagonistas mulatos. Que não o fez é coisa geralmente sabida. Seus personagens negros são escravos ou domésticos e apenas em um dos seus romances e quatro dos seus contos aparecem personagens de uma importância pouco acima de secundária.
\end{abstract}

De fato, em Machado a temática negra não está enunciada no enunciado de maneira facilmente visível; há mesmo quem diga que ele silenciou essa questão. $\mathrm{O}$ semioticista atento não se deixa enganar pela aparente invisibilidade temática ou figurativa. É preciso ir além, buscar nos intersdícios, pois é na enunciação que esse enunciador se projeta. Recriações de estereótipos a exemplo do "negro feiticeiro", em D. Casmurro, do servilismo do negro ("humildade nas suas cortesias", em Papéis Avulsos); negros infiéis ou traiçoeiros, em Papéis Avulsos e Memorial de Aires; paternalismo dos brancos, a infantilização no tratamento do branco para com o negro (a senhora branca que foi boa para eles), etc. Esse jogo de enunciação vs. enunciado requer atenção redobrada e uma boa dose de elementos da Pragmática, tais como as teorias da pressuposição, do implicitamento, do subtendido, além de todos os elementos do nível discursivo do percurso gerativo do sentido. Importa realçar, no entanto, que seu quererparecer adequado à tradição literária legitimada foi sancionada positivamente pela crítica da época e da atualidade. Com relação a até que ponto sua obra contribui para o debate a respeito da formação de uma literatura negra, isso sim é uma grande incógnita.

$\mathrm{Na}$ seqüência da exposição desse primeiro modelo, passemos agora para o percurso do camaleão, cuja modalidade projeta um querer-ser. O perfil do camaleão é bastante controverso. Não estamos nos referindo ao aspecto pejorativo atribuído à idéia de camaleão pelo senso comum, qual seja, algo ou alguém despersonalizado, que vulgarmente "anda conforme o vento sopra". É preciso lembrar ao leitor que os quatro estilos de vida tratados aqui, recriam a proposta de Landowski e, portanto, são termos semiotizados. O estilo camaleão seria aquele (p.38)

cuja habilidade consiste, muito discretamente, em se fazer passar por alguém que já pertence ao mesmo mundo, embora, na realidade, ele jamais tenha se disjunto do universo - totalmente outro - de onde ele provém e para onde, 
secretamente, ele sabe (ou imagina) poder um dia retornar com um dia se volta para casa.

Cruz e Sousa parece representar bem o grupo. A tematização poética de Cruz e Sousa é recoberta por figurativizações que fogem à carga sígnica brasileira. Roger Bastide irá dizer que ele parece "o mais europeu de todos os poetas brasileiros". Em seus versos são fartos os temas que euforizam a cor branca, como no verso a seguir (Sousa, 1981:74)

\section{BRAÇOS}

Braços nervosos, brancas opulências, Brumais brancuras, fulgidas brancuras, Alvuras castas, virginais alvuras, Lactescências das raras lactescências.

Além disso, ele é leitor assíduo de escritores europeus com os quais vai aprender o pensamento simbolista. Em sua poesia é muito forte a presença de recursos sonoros. Cruz e Sousa busca a afirmação no universo canônico, mas sua origem racial torna-se um empecilho. Nesse sentido, o escritor nega a disjunção e se encontra no sentido em direção à conjunção desse modelo. Seria leviano omitir que, atualmente, há pesquisadores revisitando a obra tanto de Machado de Assis quanto de Cruz e Sousa, em busca de novas leituras a respeito do tratamento temático e figurativo de elementos raciais presentes nas respectivas obras. Exploraremos esse tópico em trabalhos posteriores.

Tratando dos dois últimos estilos, o dândi e o urso, podemos dizer que o nome mais indicado para esse momento é Luiz Gama. Um olhar pouco atento diria que Gama representa bem o estilo dândi, dado sua contundência e intervenção satírica na poesia, se colocado como avesso às formas padrões de escrita, e crítico contumaz do modelo social em vigor no período da escravidão. No entanto, nossa proposta difere dessa. Aceitar Gama como dândi é sinônimo de admitir que ele demarca um projeto de intervenção contínuo e deliberadamente oposto ao estilo do esnobe, vindo, por exemplo, a se configurar como uma matriz alternativa de performance literária. Em outras palavras, teríamos de admitir que ele instaura uma literatura negra. Esse raciocínio corre o risco de estar contaminado com um anacronismo improcedente, visto que no final do século XIX não se falava na existência de uma literatura negra e, conseqüentemente, não havia um perfil de dândi. A postura de Gama, configurada por um jeito singular de atuar se aproxima do jeito urso de ser, pois está, nesse sentido, percorrendo o caminho da negação da conjunção com o marco referencial canonizado, e seguindo em direção à disjunção total desse modelo. Essa tentativa de disjunção aponta pistas de intervenção para as gerações futuras, especialmente, para os poetas de Cadernos Negros. Portanto, Luiz Gama preparou o caminho para um sistema de literatura que vai reler a

matriz ocidental e vai apontar outro paradigma poético. Filho de Luisa Mahim, africana livre que resistiu ao batismo católico e foi uma das lideranças da Revolta dos Malês, na Bahia, e de um fidalgo baiano de origem portuguesa. Segundo Camargo (1987:44) "como lírico, é o primeiro poeta negro a cantar seu amor por uma mulher de sua própria 
raça". Eis seu poema mais famoso "Quem sou eu?" - mais conhecido como "Bodarrada"

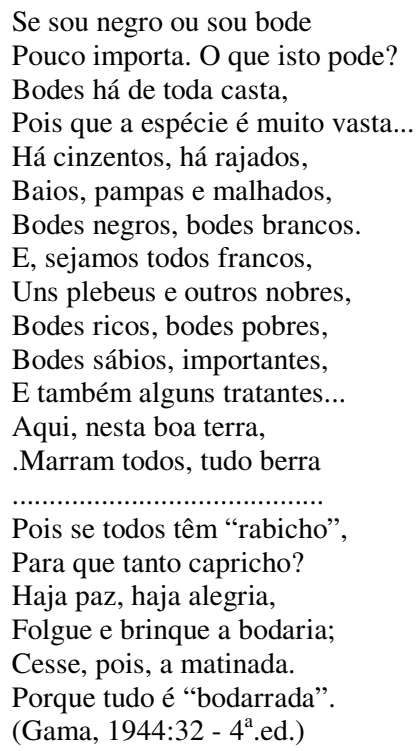

Em plena escravidão, Gama recorria à ironia desmedida para enunciar suas sátiras, preocupando-se com o plano de expressão e o plano de conteúdo, pois era atento aos efeitos de sentido produzidos no plano de expressão, como diz José Romão da Silva:

"sem a preocupação pela gramática e pela pompa formal do parafraseado refeito, abjurando mesmo a idolatria da frase, Luis Gama amava o ritmo, a boa cadência, o vocábulo sonante, no lugar adequado.” (2004:25)

Se sistematizamos esse primeiro modelo no quadrado semiótico percebemos que um dos lados das categorias encontra-se em estado de espera

\begin{tabular}{cc} 
Estilo-Esnobe & \multicolumn{1}{c}{ Estilo- Dândi } \\
Machado de Assis & $?$ \\
Conjunção & Disjunção \\
& \\
& \\
Estilo Camaleão & \\
Cruz e Souza & Estilo Urso \\
Não-disjunção & Luiz Gama \\
& Não-conjunção
\end{tabular}


Convém notar que se mudamos o marco referencial e testamos a matriz alternativa de estética literária, incorporando a projeção da literatura negra, muda a configuração da proposta. Nesse segundo modelo, Machado de Assis não é mais esnobe, posto que ele não se adequa a essa perspectiva. Seu percurso agora é o do dândi, cujo esforço é não só ser o oposto do que se espera dele, mas ele precisa parecer que é diferente. Com relação à identificação com a temática negra, Machado entra em disjunção total. No outro lado do contraponto está a atuação do esnobe que se orgulha de pertencer ao grupo, que se esforça não somente para ser, mas para parecer que é um divulgador da idéia. Esse perfil é representado pelo grupo de poetas que seguiu as pistas indicadas por Luiz Gama, e produz o alternativo, o outro modelo. Esse grupo é composto pelos poetas de Cadernos Negros.

Na década de 70, surge uma safra de enunciação negra que marcará o século XX e se transportará para o século XXI: o gaúcho Oliveira Silveira, o mineiro Adão Venturo e o paulista Abelardo Rodrigues já davam pistas de que havia sim uma literatura negra em ebulição. No final dessa década, foi editado o primeiro dos 27 volumes de Cadernos Negros. Arriscaríamos dizer aqui, que esse universo cujo auge foi o lendário ano de 1978 reúne, desde então, o grupo de poetas cuja marca é a afirmação de um estado conjuntivo permanente, afirmado pela figura do "esnobe".

Vejamos uma poesia de Cuti, um renomado poeta da geração atual. O poema "Arremedo" parodia o "Poema de Sete Faces", de Carlos Drummond, e instaura o diálogo intertextual e interdiscursivo, numa narrativa cortante e de forte posicionamento político, mas não sem antes reconstruir a mesma estrutura do poema drummoniano, sobretudo em sua dimensão rítmica e sua curva entoativa.

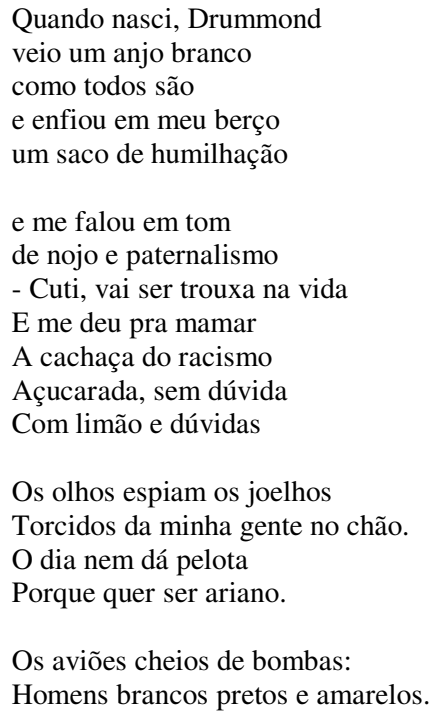




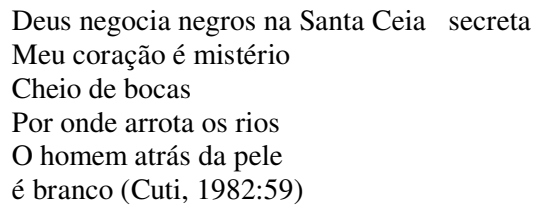

Adentrar o percurso da negação da conjunção, mas sem ainda chegar à disjunção total é o caminho do urso. O estilo urso de ser é o perfil de poeta que produz uma enunciação negra, adota temas e figuras que remetem à literatura negra, mas não reivindica participar do grupo. Ele tende mesmo a se disjungir. Dois nomes parecem indicados: Ricardo Aleixo e Antônio Risério. A opção desse perfil de poeta é construir um ethos mais eufemístico, sem aparecer muito, sem que ao seu lado esteja inscrita a marca do grupo. Em outras palavras, trata-se de um criador de literatura negra, mas, ao instaurar uma enunciação que transita em diversas outras temáticas, não reivindica para si o querer-parecer ser um poeta negro. O urso prefere trabalhar sozinho, não gosta de aglomerações, sua presença é estrategicamente pensada, e ele adora romper com instituições. Nesse sentido, ele não se coloca como representante de ninguém e não admite que o representem. Ele está por ele mesmo, e parece mesmo preferir a semiótica ilusão da soberania.

Analisemos Ricardo Aleixo. Além de poeta, Aleixo é compositor e performer. Em todos os seus livros, ele responde pela iconografia (projeto gráfico e editoração eletrônica). Cada livro reúne no plano de expressão e no plano de conteúdo elementos de enunciação negra. Embora o autor real negue a conjunção com uma literatura negra, para a semiótica isso não interessa. A análise semiótica está interessada no que é projetado pela obra, independentemente da intenção do autor. A nenhum destinatário é concedida a proeza de saber o que se passa na cabeça do autor. Em Trívio, Aleixo marca no enunciado a preocupação com a temática negra:

$\begin{array}{ll}\mathrm{q} & \text { uanto + } \\ \mathrm{p} & \text { obre + } \\ \mathrm{n} & \text { egro } \\ \mathrm{q} & \text { uanto }+ \\ \mathrm{n} & \text { egro + } \\ \mathrm{a} & \text { lvo } \\ \mathrm{q} & \text { uanto + } \\ \mathrm{a} & \text { lvo }+ \\ \mathrm{m} & \text { orto }+ \\ \mathrm{q} & \text { uanto + } \\ \mathrm{m} & \text { morto }+ \\ \mathrm{u} & \mathrm{m}\end{array}$

(Aleixo, 2002:69)

Atento à expressividade cromática, o poema foi escrito com letras brancas sob o fundo preto. Homologa-se à categoria semântica vida vs. morte, elementos do conteúdo, mas, sobretudo, elementos da expressão: duas colunas, uma formada pela letra inicial e outra como o resto da palavra, seguida de um sinal matemático mais (+), 
formando duas isotopias: a soma dos elementos e também a cruz, que remete à morte. Assim, na poesia de Aleixo a relação semi-simbólica é mais explícita, mas no plano de conteúdo apreende-se uma verdadeira preocupação com temas defendidos pelo grupo dos "esnobes", cada um à sua maneira.

Nosso último modelo é o estilo camaleão. No modelo referencial atual, o camaleão insere-se no percurso da negação da disjunção e se aproxima da conjunção. Deduzimos desse perfil, aqueles poetas que dialogam mais intimamente com a literatura negra, estabelecendo parcerias importantes. Embora eles não reivindiquem a posição de produtores de literatura negra, também não questionam a possibilidade do diálogo. Pensamos em Edimilson de Almeida Pereira e Anelito de Oliveira para representar o grupo camaleão. Pereira é autor de livros de poesia, literatura infanto-juvenil, professor universitário e um incansável pesquisador do universo banto (mundo de inquices, calundu, congado e calunga). De sua autoria, destacamos "Inquices" (1996:15)

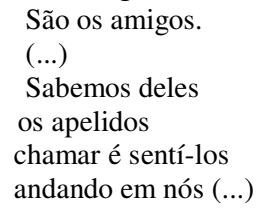

À guisa das consideraçõs finais, é importante dizer que não tencionamos o estatuto do absoluto, do certo, do acabado, nas discussões esboçadas nesse texto. As discussões a respeito da literatura negra são complexas; o que se pretende é que a semiótica ofereça mais um simulacro metodológico para se discutir tal produção literária. Note que construímos uma proposta sem a devida preocupação com a presença feminina no universo literário brasileiro. Deixamos de mencionar escritoras importantes, tais como Leda Maria Martins, Conceição Evaristo, Elisa Lucinda, Esmeralda Ribeiro, Geni Guimarães, Míriam Alves, entre outras. Feitas as ressalvas relevantes, apresentamos o modelo alternativo de referência, no qual se encontram e se completam os quatro percursos do quadrado. Assim, no lugar onde havia um ponto de interrogação, uma lacuna, o preenchimento do vazio (com a inclusão de uma dicção negra na literatura brasileira) projeta o efeito de sentido de liquidadação da falta. Do ponto de vista semi-simbólico, tal efeito propõe um novo olhar para o que transitava no plano da invisibilidade, e que agora, está exposto no enunciado e na enunciação. 


\begin{tabular}{rr} 
Estilo-Esnobe & \multicolumn{1}{c}{$\begin{array}{l}\text { Estilo- Dândi } \\
\text { Poetas Cadernos Negros } \\
\text { Conjunção }\end{array}$} \\
& $\begin{array}{l}\text { Machado de Assis } \\
\text { Disjunção }\end{array}$ \\
Estilo Camaleão & Estilo Urso \\
Edimilson A. Pereira & Ricardo Aleixo/ \\
Anelito de Oliveira & Antônio Risério \\
Não-disjunção & Não-conjunção
\end{tabular}

\section{REFERÊNCIAS BIBLIOGRÁFICAS}

ALVES, Míriam. (2002). Cadernos Negros (número 1): estado de alerta em fogo cruzado. In:

FIGUEIREDO, Maria do Carmo Lana e FONSECA, Maria Nazareth Soares (org.). Brasil

Afro-Brasileiro. Belo Horizonte: Autêntica.

ALEIXO, Ricardo. (2002). Trívio. Belo Horizonte: Scriptum.

BARROS, Diana Luz Pessoa de (1990). Teoria semiótica do texto. São Paulo: Ática.

São Paulo: Humanitas.

(2001). Teoria do discurso - fundamentos semióticos.

BASTIDE, Roger.(1943). A poesia afro-brasileira. São Paulo: Martins Fontes.

BERND, Zilá. (1988). (org) Introdução à Literatura Negra. Porto Alegre: AGE/IEL.

BROOKSHAW, David. Raça e cor na literatura brasileira. (1983). Porto Alegre:

Mercado Aberto, Grafica Geral. São Paulo, Cultrix.

CAMARGO, Oswald.(1987). O negro escrito. São Paulo: Secretaria de Estado da-

Cultura, Imprena Oficial.

BOSI, Alfredo.(2002). Literatura e Resistência. São Paulo:Companhia das Letras.

CADERNOS NEGROS - 1978 a 2003.

CUTI. (1982).BATUQUE DE TOCAIA. São Paulo: Ed. do Autor.

DUARTE, Eduardo de Assis. (2002). DUARTE, Eduardo de Assis \& SCARPELLI, Marli Fantini.

Poéticas da Diversidade, Belo Horizonte, Editora UFMG.

FIORIN, José Luiz. (1990).Linguagem e Ideologia.2 ${ }^{\mathrm{a}}$. edição, São Paulo:Ática.

FONSECA, Maria Nazareth Soares. (2000)Visibilidade e ocultação da diferença: imagens do negro na cultura brasileira. In: FONSECA, Maria Nazareth Soares (org.). Brasil Afro-Brasileiro. Belo Horizonte: Autêntica.

LANDOWSKI, Erick. (2002). Presenças do Outro. São Paulo:Perspectiva.

MARTINS. Leda Maria. (1995). A cena em sombras: teatro negro no Brasil e nos EUA. São

Paulo Perspectiva.

ORLANDI, Eni Puccinelli. (1995). As formas do silêncio - no movimento dos sentidos.

Campinas-SP: Editora da Unicamp. 
PEREIRA, Edimilson de Almeida. (2002). "Cantopoemas: uma literatura silenciosa no Brasil

In: FONSECA, Maria Nazareth Soares (org.). Brasil Afro-Brasileiro. Belo Horizonte:

Autêntica.

Horizonte:

Mazza Edições.

PROENÇA FILHO, Domício.(1988). O negro na literatura brasileira. Boletim bibliográfico Biblioteca Mário de Andrade. São Paulo: Biblioteca Mario de Andrade, v.49, no. 14 .

RABASSA, GREGORY. (1958). O negro na ficção brasileira. Rio de Janeiro:Tempo Brasileiro,

1965.

SAUSSURE, F. de s.d. Curso de Lingüística Geral. São Paulo, Cultrix.

SAYERS, Raymond. (1958). O negro na literatura brasileira. Rio de Janeiro: O Cruzeiro.

SILVA, Júlio Romão da. Crítica à Crítica de Luiz Gama. (2004).5ª.ed.Teresina: Ed. Júnior.

SOUSA, Cruz. Obra completa.

\section{Como citar este artigo:}

LORENSO, Silvia Regina Castro. Literatura negra sob a perspectiva semiótica: o dito e o não-dito. Estudos Semióticos, Número 2, São Paulo, 2006. Disponível em <www.fflch.usp.br/dl/semiotica/es>. Acesso em "dia/mês/ano". 